\title{
Validasi Dan Pengembangan Paradigma Eksperimen Learned Helplessness Pada Etnis Dominan Di Indonesia
}

\author{
Galang Lufityanto \& Wenty Marina Minza \\ Center of Indigenous \& Cultural Psychology, \\ Fakultas Psikologi, Universitas Gadjah Mada \\ galanglufityanto@ugm.ac.id
}

\begin{abstract}
Learned helplessness (LH) is known as a phenomenon in which participants feel powerless toward the conditions occurred to them. While the phenomenon can be attributed to other psychological phenomena such as depression, etc. little is known whether specific context would explain (i) what the cause of (LH) and (ii) what strategy employed by individuals to cope with LH. Our study is intended to examine the two above questions in the dominant ethnicity in Indonesia, i.e. Javanese. Sixty participants were interviewed with open-ended questionnaire following indigenous psychology approach. We found that family was the greatest cause of LH in our sample. Further spiritual activities were employed by our participants to deal with their feeling of powerless.
\end{abstract}

Keywords: learned helplessness, indigenous psychology, family, spirituality.

\section{PENDAHULUAN}

Fenomena demoralisasi mudah dijumpai dalam berbagai macam konteks kehidupan bermsyarakat di Indonesia. Penelitian yang dilakukan terhadap Pegawai Negeri Sipil (PNS) di Indonesia pada era pemerintahan Soeharto menunjukkan bahwa tingkat kinerja yang rendah dan tindakan korupsi yang terjadi di lingkungan kerja salah satunya disebabkan karena ketidakberdayaan para pegawai menghadapi sistem yang minim unsur akuntabilitas dan transparansi (Budiman, Roan, \& Callan, 2013). Lebih jauh lagi, frustrasi karena upaya yang dilakukan berkali-kali namun tidak kunjung mendapat hasil yang baik akan menyebabkan seseorang mengalami ketidakberdayaan (Sidi \& Setiadi, 2013). Ketidakberdayaan tersebut pada akhirnya melahirkan disonansi kognitif hingga akhirnya berujung pada manifestasi perilaku yang maladaptif dalam diri PNS tersebut.

Studi-studi klasik aliran Behaviorisme telah menunjukkan bahwa pengkondisian (conditioning) tertentu dapat mempengaruhi perilaku pada lintas jenis spesies. Salah satu percobaan yang dilakukan oleh Maier and Seligman (1976) menunjukkan bahwa dengan pengkondisian tertentu, subjek dapat dibuat merasa tidak berdaya suatu fenomena yang kemudian dikenal dengan istilah learned helplessness (LH). Fenomena ini terjadi tatkala subjek dihadapkan pada kondisi ketika apa pun yang mereka perbuat tetap tidak akan bisa menghindarkan mereka dari situasi tidak menyenangkan (aversive). Dengan pengkondisian berulang, subjek menjadi kehilangan motivasi untuk berusaha, alih-alih cenderung menjadi pasrah dalam menerima perlakuan yang tidak menyenangkan. Paradigma LH yang pertama kalinya diujicobakan pada subjek hewan ini kemudian dikembangkan pada subjek manusia dengan menggunakan manipulasi eksperimen yang beragam (Cohen, Rothbart, \& Phillips, 1976; NolenHoeksema, Girgus, \& Seligman, 1986; Peterson \& Seligman, 1983).

Lebih lanjut lagi, paradigma LH ini dipakai untuk menjelaskan atribusi 
dalam sikap manusia (Hiroto, 1974) yang terkait dengan beberapa variabel psikologis manusia termasuk di antaranya kecenderungan untuk percaya pada hal-hal mistis (Matute, 1994), perasaan tidak berdaya (Peterson \& Seligman, 1983), dan bahkan hingga fenomena klinis seperti misalnya gejala depresi (Klein, Fencil-Morse, \& Seligman, 1976; Nolen-Hoeksema et al., 1986). Salah satu outlet depresi, misalnya dysthimia, atau gejala depresi persisten yang kronis namun tidak terlalu parah (persistent depressive disorder), ditemukan terjadi karena individu yang bersangkutan mengalami learned helplesness dan kemudian mengalami over-generalization (Diener, Kuehner, Brusniak, Struve, \& Flor, 2009).

Meskipun pada akhirnya, studi terkait LH telah beranjak ditinggalkan dan orang cenderung tertarik untuk meneliti fenomena Learned Optimism (Niranjana \& Pattanayak, 2005; Reivich \& Gillham, 2003; Seligman, 2011), namun tetap diperlukan pengayaan kajian terkait fenomena LH dikarenakan masih banyak fenomena di masyarakat yang diduga berakar dari kondisi di mana masyarakat merasa tidak berdaya. Kondisi ketidakberdayaan tersebut tidak akan serta merta hilang dengan jalan menyuntikkan perasaan optimisme tanpa didahului dengan usaha untuk mencari akar penyebab perasaan tidak berdaya tersebut.

Salah satu tujuan penelitian ini adalah untuk menyelidiki fenomena perasaan tidak berdaya atau LH yang mungkin terjadi di Indonesia dalam konteks yang lebih umum. Bahkan kajian terkait LH secara global sendiri masih mendapatkan beberapa kritik yang umumnya berpangkal dari ketidakacuhan peneliti terhadap konteks budaya dan lingkungan yang turut membentuk pola pikir individu yang diduga mengalami LH (Abramson, Seligman, \& Teasdale, 1978). Misalnya, tidak selamanya kondisi yang membuat individu dari suatu latar budaya mengalami tidak berdaya akan menyebabkan individu lain dari beda latar budaya akan mengalami hal serupa. Mempertimbangkan hal di atas, maka pemahaman terhadap fenomena LH dari konteks yang spesifik, yaitu Indonesia, akan turut membantu dalam memahami dinamika psikologis masyarakat Indonesia baik secara mikro maupun makro terkait dengan permasalahan sosial yang terjadi akhir-akhir ini. Sejauh pengetahuan peneliti, sampai saat ini belum ditemukan studi terkait fenomena perasan tidak berdaya di Indonesia dalam perspektif psikologi atau ilmu perilaku. Dengan demikian, penelitian ini memiliki nilai strategis bagi pengembangan penelitianpenelitian selanjutnya yang berangkat dari perspektif psikologi. Terlebih lagi, penelitian ini akan menjadi yang pertama dalam memvalidasi paradigma penelitian LH pada konteks masyarakat Indonesia. Beberapa penelitian sebelumnya menemukan pengaruh antara tingkat spiritualitas individu terhadap LH (Matute, 1994). Dengan demikian paradigma ini sangat cocok untuk dikembangkan di Indonesia mengingat Indonesia merupakan negara yang kehidupannya sangat agamis.

\section{METODE}

Penelitian ini menggunakan pendekatan indigenous yang bertujuan untuk mengeksplorasi fenomena psikologis menggunakan perspektif lokal (U. E. Kim \& Berry, 1993). Beberapa aplikasi teori dari Barat yang hasilnya sulit direplikasi dalam konteks lokal, menyiratkan urgensitas pendekatan indigenous (U. Kim, Yang, \& Hwang, 2006) dalam memahami fenomena yang mungkin mengakar dalam kehidupan sosio-kultural masyarakat yang spesifik. 
Untuk pendekatan indigenous, peneliti berencana untuk merekrut sampel yang cukup representatif dengan mempertimbangkan etnis sebagai salah satu kriteria. Penelitian terdahulu menemukan bahwa dominansi dalam konteks kehidupan berpolitik akan cenderung menimbulkan perasaan superior (Chow, Lowery, \& Knowles, 2008). Terkait dengan konteks Indonesia, maka peneliti berencana untuk mengambil sampel etnis dominan yaitu etnis Jawa. Adapun penelitian serupa rencananya akan dilakukan pada etnis marginal pada pelaksanaan studi tahun selanjutnya.

Tabel 1 (Lampiran) menunjukkan persebaran jumlah sampel penelitian ini yaitu sebanyak 60 subjek yang mewakili kategorisasi: (i) jenis kelamin, (ii) status sosial ekonomi, (iii) latar belakang pendidikan, dan (iv) generasi. Hal ini sesuai temuan-temuan terdahulu yang menyebutkan bahwa jenis kelamin (Acker, 1990; Le Espiritu, 2001), tingkat pendapatan (Acker, 2006; Williams, Yu, Jackson, \& Anderson, 1997), dan keanggotaan dalam generasi tertentu (Kumar \& Lim, 2008) berpengaruh terhadap sikap inferioritas dan superioritas, yang pada akhirnya akan memiliki dinamika yang unik terhadap sikap tidak berdaya.

Pada awalnya, penelitian ini direncanakan untuk menemukan tiga responden untuk tiap-tiap kategori persilangan jenis kelamin $\mathrm{x}$ tingkat pendidikan $\mathrm{x}$ tingkat penghasilan $\mathrm{x}$ generasi, namun terkendala karena responden tersebut relatif susah ditemukan. Selain itu ada faktor resistensi yang cukup tinggi pada beberapa responden dari kategori tertentu sehingga tidak dimasukkan sebagai responden penelitian ini.
Terkait instrumen pengumpulan data dalam penelitian ini digunakan open-ended questionnaire yang berisi beberapa pertanyaan sebagaimana ditunjukkan pada Tabel 2 berikut :

\section{Tabel 2. Daftar Pertanyaan Open Ended Questionnaire}

\begin{tabular}{cl}
\hline No & Bunyi Pertanyaan \\
\hline 1 & $\begin{array}{l}\text { Ceritakan peristiwa atau kejadian nyata } \\
\text { yang membuat Anda merasa tidak } \\
\text { berdaya. }\end{array}$ \\
2 & $\begin{array}{l}\text { Hal-hal apa yang membuat Anda merasa } \\
\text { tidak berdaya? }\end{array}$ \\
3 & $\begin{array}{l}\text { Perilaku apa yang muncul ketika Anda } \\
\text { merasa tidak berdaya? } \\
\text { Bagaimanakah cara Anda dalam } \\
\text { mengatasi ketidakberdayaan ini? }\end{array}$ \\
\hline
\end{tabular}

Respon dari partisipan terhadap pertanyaan penelitian tersebut kemudian dianalisis menggunakan teknis analisis konten oleh tiga asisten peneliti untuk mendapatkan objektivitas dalam memahami fenomena yang akan diukur. Beberapa tahapan analisis yang dilakukan sesuai dengan Creswell (2010) adalah sebagai berikut: (i) pemrosesan dan persiapan data, (ii) analisis data secara keseluruhan untuk mendapatkan konteks global, (iii) analisis lebih detail, pemberian label serta kategorisasi/koding data, dan terakhir (iv) membuat kesimpulan.

\section{HASIL}

Melalui pertanyaan pertama ada open ended questionnaire, yaitu: "Ceritakan peristiwa atau kejadian nyata yang membuat Anda merasa tidak berdaya", didapatkan hasil sebagaimana terlihat pada Grafik 1a di bawah ini, yaitu mayoritas partisipan merasa bahwa penyebab ketidakberdayaan terkait dengan peristiwa yang terjadi di keluarga (27\%), terkait finansial $(21 \%)$, pekerjaan (19\%), kesehatan (18\%), dan relasi sosial lainnya $15 \%$ ). 


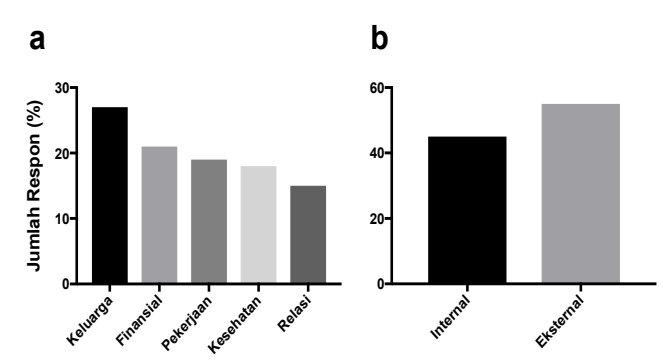

Grafik 1. Faktor penyebab terjadinya perasaan ketidakberdayaan.

Terkait dengan pertanyaan kedua, yaitu: "Ceritakan peristiwa atau kejadian nyata yang membuat Anda merasa tidak berdaya?", partisipan melaporkan bahwa kejadian-kejadian yang membuat tidak berdaya sebagian besar dikarenakan faktor internal $(45 \%)$ seperti misalnya: ketidakmampuan dalam menghadapi perubahan atau tuntutan; dan juga eksternal (55\%) seperti misalnya: kehendak Tuhan, kondisi ekonomi negara yang memburuk, dan lain-lain (Grafik 1b).

Bagaimana cara partisipan menghadapi perasaan ketidakberdayaan dan juga strategi dalam menghadapi perasaan ketidakberdayaan ini didapatkan dari pertanyaan open ended questionnaire nomor 3 dan 4. Pada pertanyaan nomor ketiga, yaitu: "Perilaku apa yang muncul ketika Anda merasa tidak berdaya?" didapatkan bahwa pada responden menjawab cenderung pasif atau tidak melakukan apa-apa (48\%); emosional (35\%) misalnya menjadi sedih; spiritual (13\%) misalnya belajar untuk lebih ikhlas dan menyerahkan diri kepada-Nya; dan berusaha mencari solusi (4\%) sebagaimana yang ditunjukkan pada Grafik 2a.
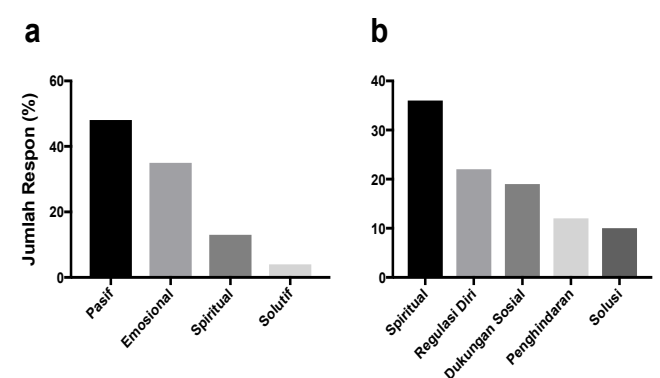

\section{Grafik 2. Perilaku dan Strategi dalam menghadapi ketidakberdayaan.}

Terkait dengan strategi dalam menghadapi ketidakberdayaan ini, Grafik 2b menunjukkan jawaban repsonden atas pertanyaan keempat, yaitu: "Bagaimanakah cara Anda dalam mengatasi ketidakberdayaan ini?" Responden melaporkan langkah spiritual sebagai strategi coping yang paling sering dilakukan (36\%), diikuti oleh melakukan regulasi diri (22\%), mencari dukungan sosial (19\%), menghindar (12\%), dan mencari solusi (10\%). Salah satu cara yang termasuk dalam strategi spiritual adalah berdoa kepada Tuhan YME, sedangkan regulasi diri di antaranya adalah belajar untuk lebih sabar.

\section{DISKUSI}

Fenomena Learned Helplessness (LH) atau yang identik dengan perasaaan tidak berdaya merupakan suatu kondisi di mana seorang individu merasa tidak bisa melakukan apa-apa dan cenderung pasif (Maier \& Seligman, 1976). Setidaknya, data responden kami melaporkan perilaku pasif pada kondisikondisi tertentu yang terkait dengan peristiwa yang terjadi dengan keluarga, finansial, pekerjaan, kesehatan, dan juga relasi sosial (misal hubungan dengan teman). Keluarga tampaknya merupakan sumber penyebab terjadinya ketidakberdayaan ini. Hal ini sesuai dengan beberapa penelitian sebelumnya yang menunjukkan bahwa orang Indonesia menganggap keluarga sebagai 
salah satu faktor terpenting dalam elemen kehidupannya (Barni, Knafo, Ben-Arieh, \& Haj-Yahia, 2014; Goodwin \& Giles, 2003) sehingga tidak heran jika permasalahan yang terjadi di lingkungan keluarga akan menimbulkan dampak psikologis yang signifikan.

Hal lain yang menarik dari penelitian ini adalah munculnya perilaku bernuansa spiritual dari kondisi tidak berdaya ini, seperti misalnya perilaku ikhlas dan menyerahkan diri kepada YME. Hal ini sesuai dengan studi terdahulu (Matute, 1994) yang menunjukkan korelasi positif antara strategi coping terhadap LH dengan kepercayaan yang sifatnya transendental. Terlebih lagi, data penelitian kami juga menunjukkan adanya kecenderungan responden untuk mengatribusikan penyebab ketidakberdayaannya ini secara eksternal. Hal ini sejalan dengan penelitian terdahulu yang menunjukkan tendensi yang sama (Abramson et al., 1978; Hiroto, 1974).

Dimensi spiritualitas bahkan ditunjukkan dalam strategi coping dalam menghadapi kondisi tidak berdaya. Perbedaan antara strategi spiritual dengan regulasi diri adalah spiritualitas cenderung mengarah pada atribusi eksternal, yaitu menyerahkan diri kepada Tuhan YME, dibandingkan dengan regulasi diri yang lebih berfokus pada atribusi internal. Mayoritas responden penelitian kami yang lebih memilih strategi spiritual daripada regulasi diri memperkuat dugaan bahwa bangsa Indonesia memiliki kecenderungan locus of control eksternal (Smith, Trompenaars, \& Dugan, 1995).

Secara umum, penelitian yang kami lakukan mengonfirmasi dan memperkuat temuan sebelumnya tentang fenomena LH, dengan temuan yang unik yaitu fokus konteks LH pada setting keluarga. Selebihnya, karakteristik LH yang ditunjukkan oleh masyarakat Indonesia cenderung mengikuti pola yang berlaku umum dan universal yaitu: memunculkan perilaku pasif dan nonsolutif. Selebihnya, terkait dengan karakteristik mayoritas bangsa Indonesia yang beragama Islam, maka tidak heran bahwa pada akhirnya mereka lebih memilih menggunakan langkap spiritual daripada strategi coping lainnya.

\section{SIMPULAN}

Learned Helplessness (LH) identik dengan perasaan tidak berdaya yang dialami oleh seorang individu dalam konteks tertentu. Perbedaan latar belakang budaya menyebabkan terjadinya keanekaragaman penyebab terjadinya LH. Penelitian kami menunjukkan bahwa faktor terbesar yang menyumbang terjadinya LH dalam konteks masyarakat Indonesia adalah keluarga. Artinya kondisi tidak ideal yang terjadi dalam lingkungan keluarga kemungkinan besar akan menyebabkan perasaan tidak berdaya.

Selain itu, penelitian kami juga menemukan bahwa partisipan cenderung pasif dalam menghadapi faktor yang menyebabkan ketidakberdayaan ini. Artinya, upaya yang dilakukan oleh partisipan tidak terkait langsung dengan penyelesaian masalah yang menjadi sumber perasaan tidak berdaya. Alihalih, strategi yang paling umum digunakan oleh partisipan kami dalam mengatasi perasaan ketidakberdayaannya adalah melalui jalan spiritualitas, seperti misalnya berdoa memohon pertolongan bagi penyelesaian masalahnya.

\section{DAFTAR PUSTAKA}

Abramson, L. Y., Seligman, M. E., \& Teasdale, J. D. (1978). Learned helplessness in humans: Critique and reformulation. Journal of abnormal psychology, 87(1), 49. 
Acker, J. (1990). Hierarchies, jobs, bodies: A theory of gendered organizations. Gender \& society, 4(2), 139-158.

Acker, J. (2006). Inequality regimes gender, class, and race in organizations. Gender \& society, 20(4), 441-464.

Barni, D., Knafo, A., Ben-Arieh, A., \& Haj-Yahia, M. M. (2014). Parentchild value similarity across and within cultures. Journal of CrossCultural Psychology, 45(6), 853867.

Budiman, A., Roan, A., \& Callan, V. J. (2013). Rationalizing ideologies, social identities and corruption among civil servants in Indonesia during the Suharto era. Journal of business ethics, 116(1), 139-149.

Chow, R. M., Lowery, B. S., \& Knowles, E. D. (2008). The two faces of dominance: The differential effect of ingroup superiority and outgroup inferiority on dominantgroup identity and group esteem. Journal of Experimental Social Psychology, 44(4), 1073-1081.

Cohen, S., Rothbart, M., \& Phillips, S. (1976). Locus of control and the generality of learned helplessness in humans. Journal of Personality and Social Psychology, 34(6), 1049.

Creswell, J. W. (2010). Research design: pendekatan kualitatif, kuantitatif, dan mixed. Yogyakarta: Pustaka Pelajar.

Diener, C., Kuehner, C., Brusniak, W., Struve, M., \& Flor, H. (2009). Effects of stressor controllability on psychophysiological, cognitive and behavioural responses in patients with major depression and dysthymia. Psychological medicine, 39(01), 77-86.

Goodwin, R., \& Giles, S. (2003). Social support provision and cultural values in Indonesia and Britain. Journal of Cross-Cultural Psychology, 34(2), 240-245.

Hiroto, D. S. (1974). Locus of control and learned helplessness. Journal of experimental psychology, 102(2), 187.

Kim, U., Yang, K.-S., \& Hwang, K.-K. (2006). Contributions to indigenous and cultural psychology. Indigenous and Cultural Psychology, 3-25.

Kim, U. E., \& Berry, J. W. (1993). Indigenous psychologies: Research and experience in cultural context: Sage Publications, Inc.

Klein, D. C., Fencil-Morse, E., \& Seligman, M. E. (1976). Learned helplessness, depression, and the attribution of failure. Journal of Personality and Social Psychology, 33(5), 508.

Kumar, A., \& Lim, H. (2008). Age differences in mobile service perceptions: comparison of Generation Y and baby boomers. Journal of Services Marketing, 22(7), 568-577.

Le Espiritu, Y. (2001). " We don't sleep around like white girls do": Family, culture, and gender in Filipina American lives. Signs: Journal of Women in Culture and Society, 26(2), 415-440. 
Maier, S. F., \& Seligman, M. E. (1976). Learned helplessness: Theory and evidence. Journal of experimental psychology: general, 105(1), 3.

Matute, H. (1994). Learned helplessness and superstitious behavior as opposite effects of uncontrollable reinforcement in humans. Learning and Motivation, 25(2), 216-232.

Niranjana, P., \& Pattanayak, B. (2005). Influence of learned optimism and organisational ethos on organisational citizenship behaviour: A study on Indian corporations. International Journal of Human Resources Development and Management, 5(1), 85-98.

Nolen-Hoeksema, S., Girgus, J. S., \& Seligman, M. E. (1986). Learned helplessness in children: A longitudinal study of depression, achievement, and explanatory style. Journal of Personality and Social Psychology, 51(2), 435.

Peterson, C., \& Seligman, M. E. (1983). Learned helplessness and victimization. Journal of Social Issues, 39(2), 103-116.

Reivich, K., \& Gillham, J. (2003). Learned optimism: The measurement of explanatory style. Positive psychological assessment: A handbook of models and measures, 57-74.

Seligman, M. E. (2011). Learned optimism: How to change your mind and your life: Vintage.

Smith, P. B., Trompenaars, F., \& Dugan, S. (1995). The Rotter locus of control scale in 43 countries: A test of cultural relativity.
International Journal of Psychology, 30(3), 377-400.

Williams, D. R., Yu, Y., Jackson, J. S., \& Anderson, N. B. (1997). Racial differences in physical and mental health: Socio-economic status, stress and discrimination. Journal of health psychology, 2(3), 335351. 